\title{
Signos do corpo: \\ Réquichot, Barthes e nós, os outros
}

Latuf Isaias Mucci

É preciso pintar, não para se fazer uma obra, mas para se ver até onde uma obra pode ir.*

Bernard Réquichot

O mental é apenas o corpo levado a um outro nível de percepção: o que Réquichot chama o "metamental'*

Roland Barthes
" "Il faut peindre, non pas pour faire une oeuvre mais pour voir jusqu'où une oeuvre peut aller".
" "Le mental n'est que le corps porté à un autre niveau de perception: ce que Réquichot appele le "méta-mental" (Barthes, Roland. L'obvie et l'obtus: essays critiques III. Paris: Seuil, 1982: 204).

Artista pouco conhecido, tanto do público não especializado quanto do mundo crítico das artes, Bernard Réquichot nasceu em $1^{\circ}$ de outubro de 1929, em Asnières-sur-Vègre, na França, e se suicidou em Paris no dia 4 de dezembro de 1961. Em seu corpo trágico, reinscreveu, portanto, o adágio latino Vita brevis, ars longa ["A vida é breve, a arte, longa"], na medida em que, morto com apenas 32 anos, não legou uma ampla arte, antes produziu algo plasticamente complexo e, sem dúvida, voltado para um fatal hermetismo que talvez, merecesse um desdobramento, não lhe tivesse a tragédia sido um último gesto, na cena do desespero. Depois de ter pintado, de 1941 a 1946, quadros com inspiração exclusivamente religiosa, Réquichot se orientou, em 1953, influenciado por Jacques Villon, para o pós-cubismo, rompendo, todavia, a partir de 1955, com o desmantelamento da forma, quando passa a compor seus primeiros relicários - Le reliquaire de la forêt (1957-58), La maison du manège endormi (1958-59), Nokto keda taktafoni (1960), Reliquaire de l'Armoire de Barbe-bleue (1961) -, que são aglomerados de pintura e de pedaços de telas já pintadas, cortadas e coladas em uma caixa de madeira, em cujo espaço asfixiante proliferam a cor e a matéria. Imensos vermes solitários que formigam em um corpo, esses relicários evocam vísceras febris. Em 1957, o inquieto artista, que também era poeta, cria, com Traços gráficos [Traces graphiques], sua "escritura ilegível" (écriture illisible), 
" (Em: Huysmans, Joris. Karl. Às avessas. São Paulo: Companhia das Letras, 1987: 273).

"(: 28).

" (Pacquement, Alfred. "Réquichot et la forme". Disponível em www.le-ter rier.net/requichot/textes/ pacquement2htm ).

- (Barthes, Roland. "Ré. quichot et son corps". Em: L'obvie et l'obtus: es sais critiques III. Ob. cit.: 189.214). emblema de toda uma arte, essencialmente incomunicável, cujo refúgio final só poderia ser o relicário da morte, buscada no abismo do suicídio. No fundo, o suicida procura, no além, uma comunicação impossível na sociedade humana; paradoxalmente, o gesto suicida se vinca de uma transcendênica inimaginável. Uma espiritualidade às avessas. Aliás, no posfácio a Às avessas [A rebours], de 1884, Joris-Karl Huysmans (1848-1907) considera a mais adequada crítica a essa sua obra aquela traçada por Jules-Amédée Barbey d'Aurevilly (1808-1889), que, em resenha publicada no Constitucional, em 28 de julho de 1884, escreveu: "Depois desse livro, não resta ao autor senão escolher entre a boca de uma pistola e os pés da cruz"*

Depois do livro vertiginoso, bíblia do decadentismo e evangelho do mais puro estericismo, Huysmans, criador do paradigmático de Des esseintes, recolheu-se, definitivamente, a uma tebaida, tornando-se oblata de São Bento. Bernard Réquichot, esteta estranho, optou, por sua vez, pela religiosidade, ou perversidade, do suicídio.

Difícil de ser nomeada, a arte de Réquichot, que viveu e trabalhou na vertigem insustentável da experimentação, sintoniza-se com a personalidade do artista, facilmente classificado por alguns como esquizofrênico, neurótico, psicótico, valores, como muito bem observa José Paulo Paes a respeito do herói-esteta, "negativos na escala do bom senso burguês, mas tornados positivos por Huysmans numa irrepetível equação às avessas"**.

Não causa espécie, então, se a obra do criador dos relicários tenha parca fortuna crítica. Além de ensaio de Alfred Pacquement*, a pesquisa em torno de Réquichot possui um ensaio semiológico de Roland Barthes (1915-1980), texto que, certamente, busca, no Hades das artes, uma Eurídice sedutora. O friccionamento do corpo de Réquichot no corpo do texto de Barthes configura o corpus do presente ensaio, de que nossos corpos efêmeros se transformam em espectadores.

Em "Réquichot e seu corpo", de 1973, ensaio que faz parte do imperdível $O$ óbvio e o obtuso*, Roland Barthes desenha uma leitura semiológica da poética de Bernard Réquichot. Ao analisar o próprio corpo que o artista dos Reliquaires projeta em sua obra, o teórico de Elementos de semiologia, de 1965, postula que a escritura passa pelo corpo, o que muito bem prova sua fascinação pelas "sematografias" [sématographies] de Réquichot. $\mathrm{O}$ ensaio em pauta se estrutura em rubricas que, no jargão 
barthesiano, designam-se lexias: "Lexia, unidade de leitura que, como escreveu R. Barthes, 'compreenderá ora alguns termos, ora algumas frases'; é definida como 'o melhor espaço possível em que se podem observar os sentidos"*. Unidade de comportamento lingüístico ou de discurso, a lexia é composta de "palavras", mas a palavra é uma unidade virtual, enquanto a lexia é uma unidade de funcionamento discursivo. "Há vários tipos de lexias: a lexia 'simples', que coincide com a palavra (e que corresponde à palavra simples e à palavra derivada da gramática tradicional); [...] - a lexia "composta', constituída por várias 'palavras' (e que corresponde à palavra composta da gramática tradicional); [...] a lexia 'complexa', que é uma seqüência fixa de 'palavras' (e que corresponde à lexicalização)”**. Em lingüística, portanto, o termo "lexia" traduz uma unidade significativa do discurso. Num sentido derivado, "lexias" designam, em Barthes, que se apropria desse significante, deslocando-o e fazendo-o girar - como é da índole de sua semiologia seminal e transgressora -, unidades de leitura que correspondem a excertos contíguos do texto privilegiado, na medida em que tudo significa, sem delegação, num grande conjunto final; segmenta-se, por necessidade de análise, em lexias (frases ou pedaços de frase) um texto-tutor infinitamente fragmentado, cuja "dimensão, empiricamente determinada, à primeira vista, dependerá da densidade das conotações, variável segundo os momentos do tex to"*. Ao contrário do modelo de análise estrutural da narrativa, o recorte arbitrário do significante textual abre o espaço da significância e descortina-se ao afloramento dos sentidos, realçando o plural do texto com sua polifonia e seu sedutor jogo intertextual, em que se tramam e dialogam códigos culturais e estéticos. A lexia representa, portanto, um recorte ao sabor da leitura, configurando uma estrutura móbil, proliferadora de conotações: o leitor faz o papel de autor, desconstruindo o texto, que, numa nova síntese, se reconstruirá. O texto, então, ganha foros de infinitude...

Lendo o ensaio de Barthes em torno de Réquichot, poderíamos designá-lo como uma rosácea de lexias, na medida em que, para tratar essa enigmática arte, o crítico-escritor de O prazer do texto (1973) a recorta não mais em seus elementos articuladores, mas antes nos signos-chave que, segundo a semiologia tutelar, constituem-na. O corpo destruído de Réquichot se projeta, dessa maneira, no texto que recorta a arte, disseminada em signos caleidoscópicos e esparsos.
" (Ducrot, Oswald \& Tzve. tan, Todorov. Dicionário enciclopédico das ciências da linguagem. São Paulo: Perspectiva, 1988: 205-6).

" (Gallison, Robert \& Coste, Daniel. Dicionário da didác tica das línguas. Coimbra: Almedina, 1983: 432).

* (Barthes, Roland. S/Z Paris: Seuil, 1979: 20). 
" (Rónai, Paulo. Não perca seu latim. Rio de Janeiro: Nova Fronteira, 1980: 77)
É significativo lembrar que o signo grego "soma" quer dizer corpo de um morto, ou cadáver, significado conservado até o século $\mathrm{V}$ antes da era cristã, quando começou a significar o torso e, logo, o corpo inteiro, à medida que a idéia de alma (psychê) se tornou comum na filosofia platônica, em que o corpo é apenas a habitação da alma imortal. Na língua inglesa, que mantém insuspeitos e eruditos signos de origem latina, a palavra corpse (corruptela ou adulterata, sem dúvida, do termo latino corpus) produz o significado de "cadáver". Já em latim, o signo "corpus", transposto para a nomenclatura da metodologia da pesquisa como o objeto, o tema, o tópico da investigação, incrusta-se num elenco de sintagmas bastante significativos, como corpus alienum ("objeto estranho, não objeto de discussão"), "Corpus Christi" ("o corpo de Cristo"), "corpus civitatis” ("conjunto de cidadãos”), "corpus criminis" ("corpo de delito"), "corpus cohaerentibus" ("coisa composta de várias outras: casa, navio), "corpus delicti” ("corpo de delito, "objeto que prova a prática do crime, conjunto das provas materiais, ou vestígios, da existência do delito"), "corpus ex distantibus" ("coisas coletivas; rebanho, floresta"), "Corpus Júris Civilis" ("compilação das leis romanas"), "corpus omni romani juris ("conjunto do direito romano"), "corpus liberum" ("pessoa livre"), "corpus possessionis" ("poder de fato sobre a coisa”), "corpus proprium" (“o próprio corpo em causa”), "corpus sine pectore" ("corpo sem alma”). No corpo polissêmico do signo latino corpus, convém ainda apontar - last but not the least-o sintagma habeas corpus (expressão assim glosada e gozada por algum amante etílico: "habeas copos"), que, traduzindo-se por "que tenhas o teu corpo", é recorte, ou lexia, de habeas corpus ad subjiciendum ("que tenhas o teu corpo para submetê-lo à corte de justiça”), referindo-se, portanto, "à garantia constitucional outorgada em favor de quem sofre ou está na iminência de sofrer coação ou violência”*. Essa expressão indica, portanto, ação para a proteção da pessoa contra violência ou ameaça de liberdade de locomoção, por meio de coação ilegal de autoridade. No Direito Romano, destinava-se a obrigar quem detivesse o liberto a apresentar-se ao pretor. Em sua humaníssima poética, Carlos Drummond de Andrade (1902-1987) insere, no poema "Aniversário de João Papini”, no poemário Esquecer para viver, o sintagma da libertação: "Lá dorme João no chão sem lã./ Estou sentindo a poucos passos/ da cadeia bem ali em frente/ e dormirá tempo e luas,/ se ruístas alvoroçados/ não soltarem pelas quebradas/ o latino grito: Habeas corpus". 
No filme Snatch:porcos e diamantes (2000) $)^{1}$, do cineasta inglês Guy Ritchie, há uma cena que se poderia interpretar como alegoria da lexia: diante da dificuldade de transportar um cadáver, o criminoso ouve de outro criminoso o aconselhamento de que deveria cortar o corpo morto em quantos pedaços possíveis, a serem empilhados, carregados e atirados aos porcos. Assim, se, conforme rezam as Sacras Escrituras, todo tex to é letra morta, o leitor, o crítico, o pesquisador devem retalhar o "cadáver" textual e vivificar suas partes, ofertando-as a inimagináveis convivas, que fruirão o brilho insuspeito de um diamante.

Com os estilhaços do corpo e da arte de Réquichot, o texto barthesiano compõe um corpo textual, tatuado de signos inquiridores. As rubricas-lexias sinalizam, todo o tempo, a presença do corpo, que trava um contraponto denso e intenso com a linguagem, resolvendo-se, ao fim e ao cabo, no corpo-linguagem e na linguagem-corpo. Afinal, não se funda a semiologia, sobretudo a semiologia barthesiana, tributária da lingüística de Ferdinand de Saussure (1857-1913), na episteme que a tudo perspectiva como linguagem, sendo o ser humano definido como ser de linguagem? Aqui, inquirimos, à luz da semiologia: qual a imagem do corpo que a obra de Réquichot, segundo Barthes, configura? Que imagem o corpo da obra de Réquichot reflete no corpo de Barthes, que escreve? Como nossos corpos-leitores lêem esses corpos em fricção? Cumpre, ainda, considerar que, pensando na sincronicidade (Jung) sígnica, as letras iniciais dos nomes de ambos os franceses envolvidos coincidem, às avessas, como se um se olhasse no espelho do nome do outro: RB (Roland Barthes) \& BR (Bernard Réquichot). Estaremos face a face com o quiasma, aquela figura de linguagem em que os termos se cruzam (de chiasmós, a letra grega "x", ou "ação de dispor em cruz"), se repetem por ordem inversa, pontuam e se contrapõem, estabelecem uma construção simétrica, reverberando significações infindas. Haverá muito mais coisas, entre uma linha e outra, entre uma palavra e outra, entre uma letra e outra, do que possa elucubrar nossa vaga semiologia... Significativamente, escrevendo sobre Réquichot e em torno de Réquichot, Barthes enuncia: "esse nome 'Réquichot' tornou-se o emblema de minha escritura corrente; nele ouço o som familiar de meu próprio trabalho"*, enunciado que sinaliza uma seduzida identificação de vida e obra. Essa citação (ou lexia)
" (Barthes, Roland. O óbvio e o obtuso. Trad. Léa Nova es. Rio de Janeiro: Nova Fronteira, 1990: 212), "ce nom de 'Réquichot' est devenu l'emblème de mon écriture courante; je n'entends plus en lui que le son familier de mon propre travail" (Barthes, Roland. L'obvie et l'obtus. Ob. cit.: 213-4). 
" (Barthes, Roland. O grão da voz: entrevistas 1962-1980. Lisboa: Edições 70: 211).

\footnotetext{
" "Beaucoup de peintres ont reproduit le corps hu main, mais ce corps était toujours celui d'un autre. Réquichot ne peint que son propre corps: non pas ce corps extérieur que le pein tre copie en se regardant de travers, mais son corps du dedans" (: 189).
}

\footnotetext{
" "la cursivité du discontinu (ce qui est répété est forcément discontinu)" (: 199)

" "ce qui dénie l'opposition théologique du corps et de l'âme: c'est le corps sans opposition, et donc, pour ainsi dire, privé de sens: c'est le dedans as sené comme une gifle à l'intime" (: 189).
}

remete igualmente às marcas proustianas - o único texto que Barthes escreveu sobre o autor de Em busca do tempo perdido (1913-1927) versou sobre os nomes próprios - na escritura de Barthes, que declara: "É verdade que tenho, com os nomes próprios, uma relação que me é enigmática, que pertence à categoria da significância, do desejo, talvez mesmo da fruição. A psicanálise ocupou-se muito destes problemas e sabemos muito bem que o nome próprio é, assim se pode dizer, uma avenida nobre do sujeito e do desejo"**

Próprios e/ou impróprios, os nomes fazem o corpo circular, tremer, gozar.

Uma epígrafe esfíngica, retirada do discurso cifrado de Réquichot: "Je ne sais pas c'qui m’quoi” - como traduzir essa esdrúxula frase? Aventuremo-nos e seremos devorados pelo não-sentido de um irritante anacoluto: "Eu não sei o que me quê" -, coroa o discurso de Barthes: "Muitos pintores reproduziram o corpo humano, mas reproduziam sempre o corpo de um outro. Réquichot pinta apenas o seu próprio corpo: não esse corpo exterior que o pintor copia olhando-se de lado, mas seu corpo por dentro", essa enunciação categórica inaugura "Réquichot e seu corpo" e sinaliza o teor do texto, voltado para um corpo interior em convulsão, em revolução, em entrega abissal, não ao outro, mas a si próprio, à sua obra, incompleta e inconclusa.

Mandala, o texto semiológico de Barthes em torno da obra rapsódica de Réquichot aglomera signos de diversos tipos: signos escatológicos, signos metalingüísticos, signos poéticos, que tramam a escritura atravessando o corpo do artista, o corpo do crítico do artista e o corpo do leitor, nossos corpos-leitores, nossos corpos-signos insignes. As grandes lexias - "O corpo", "As duas fontes da pintura”, "A representação", "O artista” e "A assinatura" - recortam-se, por seu turno, em outras lexias, levando a uma desconstrução do que jamais terá sido uno: "a cursividade do descontínuo (tudo o que é repetido é, por força, descontínuo)* Depois de ter trabalhado sob uma poética teológica, Réquichot opta por um excesso de materialidade, que ele mesmo denomina "metamental", definido por Barthes como “aquilo que nega a oposição teológica entre o corpo e a alma: é o corpo sem oposição, e, logo, privado de sentido: é o dentro aplicado, como uma bofetada, ao intimo"*. Quase choca o fato de o ensaio marcar-se por um traço escatológico, não mais a escatologia no sentido de final dos tempos, ou apocalipse, antes 
conotativamente como excrementos, numa polissemia que afere o corpo com seus dejetos. Sem falsos pudores, o texto barthesiano, que faz referência, inclusive, ao ânus* ${ }^{*}$ indicia a repugnância à la Sade, resultando no "gosto do asco", abrindo-se "para uma vertigem (vertigem é aquilo que não tem fim: desliga-se do sentido, deixa-o para mais tarde)"*. Nesse passo, Barthes, semiólogo de boa cepa, insere seus elementos de semiologia, à medida que especula, sempre, sobre o sentido, que se desloca, que se adia, que se nos escapa, no redemoinho do texto, seja esse tex to literário, plástico ou de qualquer outra natureza. Ao insistir na "verdade etimológica" da colagem, a obra do artista dos relicários produz, com seu fervilhar de vermes, ninhos de cobras, ninho de vespas, o resinoso, o viscoso, o nauseabundo e também - por que não? - o luxuriante. Na comparação entre a pintura e a cozinha, o texto alude aos estados do alimento, ingerido, digerido, evacuado, estando presentes, no bolo digestivo, além do cristalizado, do rachado, do fibroso, da papa granulosa, "o excremento ressecado, terroso, o ondulado gorduroso, a chaga, o borrifo, a entranha”" Assim como há, na arte de Réquichot, um “movimento erétil”, na medida em que pintar significa para ele a tensão do gozo à deriva, Barthes observa nessa arte uma vontade de vômito, relaxamento outrora talvez designado como catarsis. Aqui, lembro-me de uma pergunta que fizeram a Juarez Machado sobre por que vivia em Paris, ao que o artista brasileiro respondeu: "Paris me deixa de pincel duro!". O termo "tensão” encontra seu outro na gíria, também corporal, "tesão”, que remete a “teso”, "rígido”, "hirto”, um vasto elenco da sinonímia da virilidade na ternura da arte. Ainda sob o código da escatologia, rege-se, por exemplo, o filme $O$ cozinheiro, o ladrão, sua mulher e o amante (1989), do cineasta inglês Peter Greenaway, em que o gângster Albert Spica, interpretado por Michael Gambom, perpetra toda espécie de violência contra sua mulher Georgina, vivida por Helen Mirren, que o trai com um livreiro, freqüentador assíduo do restaurante Le Hollandais, espaço da narrativa cinematográfica. Sobre esse filme, Ivana Bentes declarou à revista Set que "poucas vezes o cinema foi tão radical e sublime ao descrever a sordidez, a violência, a degradação e a humilhação dos corpos, o medo e o poder arbitrário”. Já a revista Veja considerou que, “em meio aos desvarios de Spica, ao sangue e à violência, $O$ cozinheiro, o ladrão, sua mulher e o amante é um filme refinado e formal, repleto de maneirismos, um açougue instalado numa butique
(: 196)

"(: 192), "goût du dégoût",

"à un vertige (le vertige est ce qui ne finit pas: décroche le sens, le remet à plus tard" (: 192).

* "I'excrément séché, ter. reux, la moiré huileuse, le chancre, l'éclaboussure, l'entraille" (: 196). 
* “la langue, c'est le phallus qui parle", "et c'est aussi, dans le corps, au niveau de la langue, que Réquichot met en scène le language total: dans ces poèmes let tristes et dans ses collages de museaux" (: 192).
“[...] "c'est-à-dire, toute pratique qui vise à trans former la matière selon l'échelle complète de ses consistances, par des opé rations multiples Telles que l'attendrissement, la fluidi. fication, la granulation, la lubrification, produisant ce qu'on appelle en gas tronomie le nappé, le lié, le velouté, le crémeux, le croquant etc." (: 194).

" "La peinture perd alors sa spécificité esthétique, ou plutôt cette spécificité séculaire - se dévoile falla cieuse: derrière la pein ture, derrière sa superbe individualité historique (l'art sublime de la figuration co lorée), il y a autre chose : les mouvements de la griffe, de la glotte, des viscères, une projection du corps, et non seulement une maîtrise de l'oeil. Réquichot tient dans sa main les rênes sauvages de la peinture" (:195) de luxo”. Réquichot elabora uma poética que tem ressonâncias alhures: o corpo não tem limites...

Outra categoria de signos que se dissemina no ensaio barthesiano classifica-os como signos metalingüísticos, não fôra a figura de linguagem denominada "metalinguagem” a definição mesma da própria semiologia, instaurada e praticada por esse seguidor-transformador da lingüística saussureana. Linguagem sobre linguagens, a semiologia dos elementos se institui como língua secundária em torno de uma língua primária: o estudo de Barthes debruça-se, amorosamente, sobre o trabalho artístico de Réquichot, em cujo corpo vai mapeando a linguagem de uma arte criada no corpo e com o corpo. Com efeito, em “Réquichot e seu corpo”, desenvolve-se um ensaio semiológico não apenas a respeito da língua, literal ou denotativamente falando - “a língua é o falo que fala”, “e é também, no corpo, ao nível da língua, que Réquichot põe em cena a linguagem total: em seus poemas letristas e em suas colagens de focinhos" ${ }^{*}$-, mas ainda, e sobretudo, na maneira conotativa que toda leitura implica, principalmente uma leitura sob o viés semiológico. Se na sub-rubrica "Língua”, aposta na rubrica “Corpo”, tratara-se do órgão no corpo, deve haver igualmente um tratamento do sentido metafórico da língua, convertida, ou melhor, pervertida em linguagem, em linguagem-escritura, em linguagem-pintura, em linguagem-cozinha. Depois de ter abordado, pioneiramente, no fundamental Elementos de semiologia, o universo sígnico da culinária, Barthes retoma, em sua leitura de Réquichot, a cozinha como fonte da pintura: “ $[\ldots .$.$] isto é, toda a prática que$ vise a transformar a matéria de acordo com a escala completa de suas consistências através de múltiplas operações, tais como o amolecimento, o espessamento, a fluidificação, a granulação, a lubrificação, para produzir o que, em gastronomia, chamam o napé, o velouté, o cremoso, o crocante etc."*

Barthes traça uma analogia entre a operação da pintura e a operação da cozinha: em ambas, os gestos da mão comandam, arranhando, alisando, deformando. Belamente, arremata: "A pintura perde, então, sua especificidade estética, ou antes, essa especificidade - secular - revela-se enganadora: por trás da pintura, por trás de sua soberba individualidade histórica (a sublime arte da figuração colorida), há outra coisa: os movimentos da garra, da glote, das vísceras, uma projeção do corpo, não apenas um domínio do olho. Réquichot mantém, com mãos firmes, as rédeas selvagens da pintura"*. Ao negar a metá- 
fora ${ }^{*}$, o ensaio em pauta comete o que a psicanálise nomeia como ato falho, ou seja, um discurso negativo que camufla uma afirmação: o corpo, que na arte de Réquichot se metaforiza, renega-se como metáfora; o corpo do texto, que toma como corpus esse corpo insano, urde, por meio de vertiginosos deslocamentos, um jogo metafórico. Enredados nesse jogo, o corpo de Réquichot, o corpo de Barthes, o corpo da arte e o corpo do leitor espantado se representam en abyme. No fundo, no fundo, está sempre em jogo o corpo, inteiro e interior. Mais adiante, o ensaio volta à metáfora, agora assumida, deslocada de sua anterior negação: "a metáfora é a única maneira de nomear o inominável”* - e em Réquichot ocorre a polissemia desenfreada.

Aponta-se a escritura como a outra fonte, ou o duplo, da pintura. Poeta, Réquichot, à maneira de Picasso, Klee, Ernst e Michaux, escreveu (pode-se, assim, classificar isso?) coisas ilegíveis ou, melhor dizendo, inventou um código solipsista de uma indecifrável escritura. Aqui também, nega-se (rotundamente e sem falhas) a metáfora, qualquer metáfora. Pós-modernamente, enfrenta-se a metonímia ou o índice, signo de um traço, de um vestígio, de uma marca, de improváveis rabiscos. Eis digitais. Digitais de quê? Nunca se saberá. De quem? De Réquichot, artista-enigma; artista-esfinge; artista-cifra. Barthes lança mão de uma metáfora para designar a "semiografia”, a escritura metonímica de seu corpus: a espiral, cujo simbolismo "é oposto ao simbolismo do círculo: este é religioso, teológico, aquela, como círculo desviado para o infinito, é dialética: na espiral, as coisas voltam, mas em um outro nível: há retorno na diferença, não repetição na identidade"** A espiral representa, portanto, o deslocamento, gerado pela repetição do mesmo, que produzirá, no movimento, o diferente. Será a escritura, barthesianamente falando, o movimento dos signos, limitados, sem dúvida, mas cuja combinatória é infinitamente livre. Manipulador de palimpsestos, Réquichot terá legado à História textos com sentidos a serem inventados, reinventados, talvez determinados, certamente inesgotáveis, um Fausto que se recria - Réquichot é autor de um texto, precisamente chamado Faustus.

Esquadrinhando o corpo de Réquichot no corpo de sua obra, Barthes urde signos poéticos, com natureza essencialmente intertextual, na medida em que elabora um texto parafrástico, onde corpos dialógicos se friccionam, eclodindo significações em deslocamento. Designada como palimpséstica, a arte do criador dos Reliquaires se define, dinamicamente, como " "la métaphore est la
seule façon de nommer
l'innomable" (: 205).

" "est opposé à celui du cercle; le cercle est religieux théologique; la spirale, comme cercle deporte à l'infini, est dialectique: sur la spirale, les choses reviennent, mais à un autre niveau: il y a retour dans la différence, non ressament dans l'identité" (: 199). 
" "dans le fuillis du Texte immense qui s'écrit sans relâche, sans origine et sans fin" (: 214).

" "l'art n'est que le débat varié de l'image et du nom" (: 214). quadro dentro do quadro, escritura dentro da escritura, telas dentro de telas, caixas dentro de caixas, constituindo uma série de encaixes na grande moldura intertextual da arte, que dialoga com séculos, escolas, estilos, o que reinscreve, à sua maneira, a tradição do novo ou a tradição sempre nova, a outra coisa na coisa. Signo poético, o intertexto significa o reconhecimento do outro no mesmo e vice-versa, ou como quiasmo, do mesmo no outro, configurando uma corrente alucinatória de associações. O cubismo, a abstração, o tachismo compõem peças do mosaico intertextual da obra de Réquichot. Incompleta, essa obra se marca pela infinitude "na confusão do Texto imenso que se escreve sem descanso, sem início, sem fim"*.

A partir e em torno da arte de Réquichot, pode Barthes ponderar que, de uma ponta a outra de sua história, "a arte não é mais que o debate entre a imagem e o nome"*. Nessa conceituação da arte, uma conceituação aparentemente categórica, o significante "imagem" remete ao significante "mímesis" ou "representação", estruturando a arte figurativa, ao passo que a espessura do signo "nome" indicia a arte abstrata, em que o significante escapa e quase detona o significado. A obra de Réquichot cria um "magma abstrato": "objetos abstratos" - objetos desejosos de um nome, todavia objetos inomináveis.

Segundo Barthes, a arte de Réquichot representa, ao fim e ao cabo, o interior do corpo ou o corpo como interior, numa configuração erótica, perversa, violenta, suja, elegante, pastosa, cortante, obcecada, potente, com uma "economia suicida", na medida em que, fechando-se num hermetismo a toda prova, não busca a comunicação, ignorando a crítica, o mercado, o outro, o diálogo, enfim. Apenas duas de suas peças estão no Museu de Arte Moderna, de Paris, e sua única exposição foi possível, graças a um amigo seu. Réquichot escondia suas telas como a concha camufla a pérola.

Corpo solitário, solipsista, autarcista, o corpo da obra de Réquichot emblematiza certo corpo da arte contemporânea, com seu idioleto, com seus paradoxos, suas idiossincrasias, seus impasses, que conduzem à morte desejada, porém eloqüente, e que encontra, em "Réquichot e seu corpo", de Roland Barthes, o testamento estético de signos incinerados. Nossos corpos ficam estáticos diante de Roland Barthes e Bernard Réquichot. E em êxtase. 
Pós-doutor em Letras Clássicas e Vernáculas (USP), doutor em Poética (UFRJ), mestre em Teoria Literária (UFRJ), mestre em Ciências Sociais (Université Catholique de Louvain, Bélgica). Foi coordenador e vice-coordenador do Programa de Pós-Graduação em Ciência da Arte, da UFF, onde é professor-associado. Co-autor do e-dicionariodetermosliterarios (www.fcsh.unl.pt/edtl). Autor, entre outros livros, de Ruína § simulacro decadentista, e de ensaios de crítica literária e de arte em revistas nacionais e estrangeiras.

\section{Resumo}

Ao refletir sobre a imagem do corpo e o corpo da imagem, este ensaio promove uma leitura semiológica da análise que Roland Barthes opera em torno da obra de Bernard Réquichot: qual a imagem do corpo que, segundo o teórico de Elementos de semiologia (1965), a obra do artista dos Reliquaires (1955) estrutura? O corpo do artista fricciona-se no corpo do texto, desenhado pelo semiólogo, amador de signos.

\section{Abstract}

Studying the image of the body and the body of image, this essay does a semiological reading of the Roland Barthes's analysis of Bernard Réquichot's works: which is the image of body that, according to the author of Eléments de sémiologie (1965), the work of the artist of the Reliquaires (1955) structures? The artist's body plays in the body of the text, drawned by the semiologist, amateur of signs.

\section{Résumé}

En réfléchissant sur l'image du corps et sur le corps de l'image, cet essai réalise une lecture sémiologique de l'analyse que Roland Barthes a effectuée au sujet de l'œuvre de Bernard Réquichot: quelle est l'image du corps que, selon le théoricien des Eléments de sémiologie (1965), la production de l'artiste des Reliquaires (1955) structure? Le corps de l'artiste joue dans le corps du texte, dessiné par le sémiologue, amateur de signes.
Palavras-chave

Bernard Réquichot Roland Barthes semiologia corpo imagem.

\author{
Key words \\ Bernard Réquichot \\ Roland Barthes \\ semiology \\ body \\ image \\ Mots-clé \\ Bernard Réquichot \\ Roland Barthes \\ semiologie \\ corps \\ image \\ Recebido em \\ 19/04/2006 \\ Aprovado em \\ 09/06/2006
}

